\title{
Growth and Yield of Sweet Pepper as Influence by Different Growth Media
}

\author{
${ }^{1}$ Awuku, Bernard; Egyir, Michael
}

\author{
${ }^{1}$ University of Education Winneba, Ashanti-Manpong, College of Agriculture Education. \\ Phone: +233246429842 email: awukubernard4@ gmail. com \\ ${ }^{2}$ University of Ghana, Department of Soil Science. Phone: +233502408871 , \\ email: miki.egyir@gmail.com
}

Article No.: 111118156

Type: Research

DOI: 10.15580/GJAS.2018.11.111118156

Submitted: 11/11/2018

Accepted: 22/11/2018

Published: 03/12/2018

${ }^{*}$ Corresponding Author

EGYIR, Michael

E-mail: miki.egyir@gmail.com

Phone: +233502408871

Keywords: Growth media, greenhouse, pyrolysed, soil less media, biochar
Loss of organic matter and related loss of soil microbial diversity and activity, as a result of intensive agriculture has contributed to an increase in soil borne plant diseases. Sweet pepper is highly susceptible to many soil borne diseases such as damping-off, root rots and wilts. In view of this, the study was conducted to assess the influence of different growth media on sweet pepper in terms of growth, yield and incidence of diseases. Materials used include: Seeds of two varieties of sweet pepper (Yolo wonder and California Wonder), rice husk, coconut hull, sawdust, groundnut hull, sugarcane bagasse, top soil and well cured cow dung. The Soilless media were prepared by mixing it with cow dung in a ratio of 20:1, whilst the cow dung was applied to the top soil at a rate of $100 \mathrm{~kg} \mathrm{~N} / \mathrm{ha}$. The experiment was a two by six $\left(2^{\times} 6\right)$ factorial experiment with twelve (12) treatments replicated three (3) times resulting in a total of thirty six (36) treatments laid out in Complete Randomised Design (CRD). Parameters measured include; plant height, number of leaves per plants, number of fruits per plant, fruit length, fruit diameter and incidence of root rot and wilt diseases. The results on plant heights at various weeks after transplanting showed that, all the soilless media generally, produced plants with significantly higher height at $(p<0.05)$ than the top soil. The results also showed that, the soilless media had superior number of leaves and fruits produced per plant, fruit length and diameter to that of the top soil. There were no incidence of root rot and wilt diseases in the soilless media but the top soil had two incidence of wilt disease. The results reveals that, cultivation of sweet pepper in soilless medium can give you better growth and yield and can also reduce the occurrence of soil borne diseases like root rot and wilt in sweet pepper. Therefore, cultivation of sweet pepper in soilless medium should be encourage to reduce the occurrence of soil borne diseases in other to enhance growth and yield in sweet pepper.

\section{LIST OF ABBREVIATIONS}

$\mathrm{RH}$ - Rice Husk

$\mathrm{CH}-$ Coconut Hull

SD- Saw dust

GH- Groundnut Hull

SB- Sugarcane Bagasse

TS- Top Soil

WAT- Week After Transplanting
$\mathrm{N}$ - Nitrogen

P- Phosphorus

K- Potassium

YW- Yolo Wonder sweet pepper variety

CW- California Wonder sweet pepper variety

$\mathrm{RH}^{*}$ : Relative Humidity

NA- Not Available 


\section{INTRODUCTION}

According to Manrique (1993), sweet pepper (Capsicum annum L.) originated from Central and South America where, many species were even utilize before the arrival of Columbus. It is a fruit bearing vegetable which belong to the Solanaceae family with tomato and eggplant (Hadfield, 1993). According to Bosland and Votava (1999), sweet pepper is warm season crop, which thrive better under extended frost-free season, but it performs badly at temperature between 5 and $15^{\circ} \mathrm{C}$. Anon. (2000) also reported that, temperature of 20 $25^{\circ} \mathrm{C}$ is considered to be the optimum temperature for the crop. Sweet pepper thrives in wide range of soils, but prefers well-drained, sandy loam or loamy soil with good nutrients and water holding capacities (Hatutale, 2010). It does well in soil pH range of $5.5-6.8$ (Anon., 2000).

According to Diaz-Perez et al. (2007), green pepper fruit does not ripe once is harvested unripe. It is used in fresh salads, to add flavours to dishes and for canning (Olivier et al., 1981). In Ghana sweet pepper is used salads, curie, soup and stews. Cultivation of sweet pepper is a sour of employment and income to farmers, distributors and exporters (Lartey et al., 2005). Bell pepper can supply up to 8 percent daily allowance of vitamin A, 180 percent of vitamin C, 2 percent of calcium and 2 percent of iron (Kelly and Boylan, 2009). Capsicum pepper are great herbal medicine endowed with natural pharmacological bioactive compounds such as phytochemical, capsaicin, essential oils and a rich combination of organic micronutrients with potential health benefits (Ekwere and Udo, 2018). They are generally rich sources of antioxidants and vitamin C (Mateljan, 2018). According to Howard et al. (1994), pepper is a major source of natural colour and antioxidants compounds used in food preservation.

Loss of organic matter and related loss of soil microbial diversity and activity as a result of intensive agriculture has contributed to an increase in soil borne plant diseases (Campbell, 2006). According to Katan et al. (2002), soil borne disease causes considerable crop losses worldwide annually, and management of soil borne diseases has been identified as one of top farm management issues confronting farmers around the world. Sweet pepper is highly susceptible to many diseases such as damping-off, root rots and wilts. Root rot and wilts diseases are caused by soil borne pathogenic fungi and is one of the most serious diseases in crop cultivation worldwide (Abdel-Monaim et al., 2014). In view of this, this study was conducted to assess the impact of different growth media on sweet pepper in terms of growth, yield and incidence of diseases.

\section{MATERIALS AND METHODS}

\section{Experimental design}

The experiment was conducted in the greenhouse for the College of Agriculture Education, University of Education, Winneba Asante-Manpong campus in the Ashanti region of Ghana from December, 2017 - May, 2018. The experiment was a two by six $\left(2^{\times} 6\right)$ factorial experiment with twelve (12) treatments replicated three (3) times resulting in a total of twenty four (36) treatments laid out in Complete Randomised Design (CRD).

The treatments include: $\mathrm{RH}$ - Rice Husk, $\mathrm{CH}$ Coconut Hull, SD- Sawdust, GH- Groundnut Hull, SBSugarcane Bagasse, and TS- Top Soil

\section{Characteristics of the experimental soil}

The experimental soil was sandy loam $(66 \%$ sand, $23 \%$ silt and $11 \%$ clay) in texture, slightly acid in reaction with $\mathrm{pH} 6.3$ in water and with a bulk density of $1.7 \mathrm{Mg} / \mathrm{m}^{3}$. It was moderately fertile, being low in organic carbon $(10.2 \mathrm{~g} / \mathrm{kg})$ and available nitrogen $\left(0.9 \mathrm{~g} \mathrm{~kg}^{-1}\right)$, available phosphorus $\left(4.23 \mathrm{mg} \mathrm{kg}^{-1}\right)$ and has CEC (9.14 $\mathrm{cmol} \mathrm{kg}{ }^{-1}$ ).

Table 1. Temperature and relative humidity values in the green house

\begin{tabular}{|l|l|l|l|l|}
\hline Months & $\begin{array}{l}\text { Mean } \\
\text { Temp. } \\
\text { Max. }\end{array}$ & $\begin{array}{l}\text { Mean } \\
\text { Temp. } \\
\text { Min. }\end{array}$ & $\begin{array}{l}\text { Mean } \\
\mathrm{RH} . \\
\text { Min. \% }\end{array}$ & $\begin{array}{l}\text { Mean } \\
\text { RH. Max. } \\
\text { \% }\end{array}$ \\
\hline January & 39.3 & 22.07 & 48.92 & 90 \\
\hline February & 35.45 & 18.69 & 52.08 & 84 \\
\hline March & 35.84 & 16.69 & 52.7 & 84 \\
\hline April & 42.13 & 29.69 & 54.69 & 83 \\
\hline & & & & \\
\hline
\end{tabular}

$\mathrm{RH}^{\star}$ : relative humidity

\section{Preparation of soil less media and plant culture}

Each of the organic waste (rice hull, sugar cane bagasse, groundnut hull, sawdust and coconut hull) was mixed with cow dung in a ratio of $20: 1$ (10 kg organic material: $0.5 \mathrm{~kg}$ cow dung) and allowed to decompose for a period of 8 weeks. $2.3 \mathrm{~kg}$ of each of the medium was later used to fill $2.5 \mathrm{~L}$ bucket. $2.3 \mathrm{~kg}$ of the experimental soil was also weighed into $2.5 \mathrm{~L}$ bucket and $3.9 \mathrm{~g}$ of cow dung applied it. Holes were created at the bottom of the buckets to allow drainage. 
Table 2. Percentage N. P. and $K$ in the cow dung

\begin{tabular}{|l|l|l|}
\hline \% N & \% P & \% K \\
\hline 1.8 & 0.7 & 1.2 \\
\hline
\end{tabular}

\section{Raising of Nursery}

The sweet pepper seedlings were raised at the greenhouse in seed trays of 100 cells per seed tray filled with rice husk biochar (rice husk pyrolysed at $400^{\circ} \mathrm{C}$ in the absence of oxygen). Two weeks after germination, 19:19:19 foliar fertilizer was applied at a rate of $10 \mathrm{~g} / \mathrm{L}$ to boost growth.

\section{Transplanting of seedlings}

Seedlings were transplanted into pots at 6 weeks after sowing, at 5-6 true leaf stage; transplants were dipped into starter solution to facilitate root formation and early establishment. 75 percent moisture content was maintained in the pots throughout the experiment.

Data were collected on the following parameters: plant height, number of leaves per plants, number of fruits per plant, fruit length, fruit diameter and incidence of diseases.

\section{Statistical Analysis}

The data collected were analysed using Genstats $\left(11^{\text {th }}\right.$ edition) and the means separated at Least Significance level of $5 \%$.

\section{RESULTS AND DISCUSSION}

\section{Effect of different growth media on plant height of sweet pepper}

Among the transplanted seedlings of Yolo Wonder variety, the $\mathrm{SD}, \mathrm{GH}$ media received seedlings with initial height of $10.4 \mathrm{~cm}$ which was the highest, followed by $\mathrm{CH}$ $(10.4 \mathrm{~cm}), \mathrm{RH}(10.0 \mathrm{~cm})$, TS $(9.8 \mathrm{~cm})$ and SB $(9.7 \mathrm{~cm})$ and in that order (table 3). The TS, SB media also received seedlings with the highest initial height among the California Wonder seedlings followed by $\mathrm{SD}, \mathrm{RH}, \mathrm{CH}$ and $\mathrm{GH}$ in that order. Although, some of the transplanted seedling had higher height than others, the differences were not significant at $(p<0.05)$ table 3 . This might probably be that, all the seedlings were transplanted from a single growth medium (biochar).

In comparing the effects of the different growth media on plant height at 2 WAT among the Yolo Wonder variety, it was seen that, the $\mathrm{RH}$ medium recorded significantly higher plant height at $(p<0.05)$ than all the other media (table 3). Although, the plant height of $\mathrm{CH}$ was significantly lower than $\mathrm{RH}$, it was also significantly higher at $(p<0.05)$ than SD and TS but it was not significantly different at $(p>0.05)$ from the heights of SB and $\mathrm{GH}$. The plant heights at 2 WAT also indicated that, the TS recorded significantly lower height at $(p<0.05)$ than all the other forms of media (table 3 ). Similar trend was seen in the plant height among the California Wonder except that, in the California Wonder, the height of plant in the $\mathrm{RH}$ medium was not significantly different from $\mathrm{CH}, \mathrm{GH}$ and SB (table 3). The significantly lower plant height recorded in the SD media might be that, the sawdust comes from wood which has relatively higher lignin content which makes it a bit resistant to degradation, so probably the sawdust might still be under decomposition which could have rendered most of nutrients unavailable for plant uptake. Although cow dung was applied to the top soil (TS), it has low inherent fertility and that might have accounted for the lower plant height observed in it.

The result for plant heights at 4 WAT among the Yolo Wonder variety indicated that, the $\mathrm{RH}$ recorded the highest plant height $(34.0 \mathrm{~cm})$, which was significantly higher at $(p<0.05)$ than the heights in all the other media table 3. The $\mathrm{GH}$ media had the next highest height $(32.9 \mathrm{~cm})$ after the $\mathrm{RH}$ media and it was significantly higher at $(p<0.05)$ than $C H, S B, S D$ and TS table 3. The SB medium had the next highest height at 4 WAT after $\mathrm{RH}$ and $\mathrm{GH}$, followed by SD with the TS recording significantly lower plant heights than all the other media table 3. The GH media recorded the highest plant heights $(34.1 \mathrm{~cm})$ among the California Wonder variety, which was significantly higher at $(p<0.05)$ than the heights in all the other media table 3 . The $\mathrm{RH}$ had plant heights of $32.0 \mathrm{~cm}$ which was next to the height of $\mathrm{GH}$ and significantly higher at $(p<0.05)$ than the heights of $\mathrm{CH}, \mathrm{SB}, \mathrm{SD}$ and TS. The $\mathrm{CH}, \mathrm{SB}, \mathrm{SD}$ and TS had the heights $31.1 \mathrm{~cm}, 30.8 \mathrm{~cm}, 26.7 \mathrm{~cm}$ and $23.7 \mathrm{~cm}$ respectively, which were significantly higher at $(p<0.05)$ than each other in that order table 3. Generally, the TS had significantly lower heights at $(p<0.05)$ than all the other media.

Results on plant height at 6 WAT among the Yolo Wonder variety shown that, the $\mathrm{RH}$ had plants with significantly higher heights at $(p<0.05)$ than all the plants in the other media table 3 . The $\mathrm{CH}$ had the next higher heights $(67.8 \mathrm{~cm})$ which was significantly higher at $(p<0.05)$ than the heights of plants in $G H, S D, S B$ and TS. The SD and SB had plant height of $56.8 \mathrm{~cm}$ apiece which was significantly higher at $(p<0.05)$ than TS table 3. Similar trend was seen among the California Wonder variety except that, within the California Wonder variety, the height of plants within the SB medium was significantly higher at $(p<0.05)$ than SD table 3. 
Table 3: Effect of the different media on plant height

\begin{tabular}{|c|c|c|c|c|c|c|c|c|}
\hline \multicolumn{9}{|c|}{ Plant Height (cm) } \\
\hline \multirow[b]{2}{*}{ Medium } & \multicolumn{2}{|c|}{ Initial height } & \multicolumn{2}{|c|}{2 WAT } & \multicolumn{2}{|c|}{4 WAT } & \multicolumn{2}{|c|}{6 WAT } \\
\hline & YW & $\mathrm{CW}$ & YW & CW & YW & CW & YW & CW \\
\hline $\mathrm{RH}$ & 10.0 & 9.9 & 17.9 & 17.1 & 34.0 & 32.0 & 78.0 & 71.8 \\
\hline $\mathrm{CH}$ & 10.4 & 9.8 & 16.5 & 15.9 & 32.0 & 31.1 & 67.8 & 66.1 \\
\hline SD & 10.4 & 10.2 & 14.9 & 13.8 & 26.5 & 26.7 & 56.3 & 52.8 \\
\hline $\mathrm{GH}$ & 10.1 & 9.3 & 16.2 & 15.3 & 32.9 & 34.1 & 61.9 & 60.5 \\
\hline SB & 9.7 & 10.3 & 15.6 & 15.8 & 31.6 & 30.8 & 56.8 & 57.0 \\
\hline TS & 9.8 & 10.3 & 13.8 & 12.6 & 22.1 & 23.7 & 53.4 & 50.0 \\
\hline LSD & & & & & & & & 5.27 \\
\hline
\end{tabular}

\section{Effect of the different growth media on leaf number in sweet pepper}

The initial number of leaves per plant on the Yolo Wonder seedlings transplanted into the $\mathrm{RH}, \mathrm{CH}$ and $\mathrm{SD}$ media were significantly fewer at $(p<0.05)$ than the number of leaves on the seedlings for $\mathrm{GH}, \mathrm{SB}$, and TS media (table 4). The California Wonder seedlings transplanted into the $\mathrm{RH}, \mathrm{SD}$ and TS media had equal number of leaves (7) which was significantly lower at ( $p$ $<0.05$ ) than the number on seedlings for SB medium. But the number of leaves on seedlings for $\mathrm{RH}, \mathrm{SD}, \mathrm{GH}$ and TS media were all significantly higher at $(p<0.05)$ than that of the seedling for $\mathrm{CH}$ medium (table 4)

In comparing the number of leaves on the Yolo Wonder variety within the various media at 2 WAT. It was seen that, the $\mathrm{RH}$ medium had significantly higher number of leaves at $(p<0.05)$ than that of $\mathrm{CH}, \mathrm{SD}, \mathrm{GH}$ and TS, but it was not significantly different at $(p>0.05)$ from SB medium. The number of leaves on plants within the $\mathrm{CH}$ and SB were not significantly different at $(p>$ $0.05)$. But they were all significantly higher at $(p<0.05)$ than that of SD and TS (table 4). Among the California Wonder variety the $\mathrm{RH}$ medium had the highest number of leaves $(12)$ which was significantly higher at $(p<0.05)$ than all the plants in the other media except that of $\mathrm{GH}$ (table 4). The number of leaves on sweet pepper plants within the $\mathrm{CH}, \mathrm{SB}$ TS and $\mathrm{GH}$ were not significantly different at $(p>0.05)$ from each other (table 4). The significant differences between the number of leaves on the sweet pepper within the $\mathrm{RH}$ and other media, might be that the rice husk due to its relatively lower lignin content could have decomposed faster than the other media, making the nutrients in it available for uptake.

The results for number of leaves per plant on 4 WAT among the Yolo Wonder variety indicated that, the $\mathrm{RH}$ medium had the highest number of leaves (20) per plant. Which was significantly higher at $(p<0.05)$ than the number of leaves per plant in all the other media except $\mathrm{GH}$ (table 4). The $\mathrm{GH}$ medium had the next highest number of leaves after the $\mathrm{RH}$ and this was also significantly higher at $(p<0.05)$ than $\mathrm{CH}, \mathrm{SD}$ and TS (table 4). Among the California Wonder variety, the RH and $\mathrm{CH}$ had highest number of leaves per plant and it was significantly higher at $(p<0.05)$ than TS, SD and $\mathrm{GH}$ but they were not different at $(p>0.05)$ table 4 . Generally all the media recorded higher number of leaves per plant than TS and this could be attributed to low inherent fertility of the soil.

The results for the number of leaves per plant on 6 WAT among the Yolo Wonder variety indicated that, $\mathrm{RH} \mathrm{CH}$ and $\mathrm{GH}$ were not significantly different at $(p<$ $0.05)$, but were significantly higher than TS, SB and SD table 4. Within the California Wonder variety the $\mathrm{RH}$ recorded 71 leaves per plant which was also significantly higher at $(p<0.05)$ than all the other media (table 4$)$. The $\mathrm{CH}$ medium recorded the next higher number of leaves per plant after $\mathrm{RH}$ and this was significantly higher at $(p<0.05)$ than the number of leaves per plant observed in SD, GH, SB and TS (table 4). The GH medium had the third higher number of leaves per plant than SB, SD and TS. The TS had 50 leaves per plant which was significantly lower than all the other media (table 4). 
Table 4: Effect of the different growth media on leaf number/plant in sweet pepper

\begin{tabular}{|c|c|c|c|c|c|c|c|c|}
\hline \multicolumn{9}{|c|}{ Leave number } \\
\hline \multirow[b]{2}{*}{ Medium } & \multicolumn{2}{|c|}{ Initial } & \multicolumn{2}{|c|}{2 WAT } & \multicolumn{2}{|c|}{4 WAT } & \multicolumn{2}{|c|}{6 WAT } \\
\hline & YW & CW & YW & CW & YW & $\mathrm{CW}$ & YW & $\mathrm{CW}$ \\
\hline RH & 7 & 7 & 13 & 12 & 20 & 19 & 49 & 45 \\
\hline $\mathrm{CH}$ & 7 & 6 & 11 & 10 & 17 & 19 & 50 & 49 \\
\hline SD & 7 & 7 & 9 & 10 & 15 & 15 & 36 & 42 \\
\hline GH & 8 & 7 & 10 & 11 & 19 & 17 & 47 & 49 \\
\hline SB & 8 & 8 & 12 & 10 & 18 & 18 & 44 & 43 \\
\hline TS & 8 & 7 & 9 & 10 & 15 & 14 & 30 & 33 \\
\hline LSD & \multicolumn{2}{|c|}{0.97} & \multicolumn{2}{|c|}{1.34} & \multicolumn{2}{|c|}{2.02} & \multicolumn{2}{|c|}{6.7} \\
\hline
\end{tabular}

Effects of different media on number of fruit, fruit length and diameter of sweet pepper

At harvest, the result on number of fruit per plant among the Yolo Wonder variety indicated that, the $\mathrm{RH}$ and $\mathrm{GH}$ media recorded the highest number of fruit per plant (10) followed by $\mathrm{CH}$ and SB media (table 5). The SD medium had 8 fruits per plant which was the third highest number of fruits per plant than the TS (table 5). The $\mathrm{RH}, \mathrm{CH}, \mathrm{GH}$ and SB media had 11 fruits each per plant, which was the highest among the California Wonder variety. The SD had 9 fruits per plants which was the second highest number of fruits per plants after $\mathrm{RH}, \mathrm{CH}, \mathrm{GH}$ and SB, with the TS recording 7 fruits per plants which was the lowest among the California Wonder variety (table 5). Generally the TS recorded the lowest number of fruit per plants in both varieties and this can be due to the low inherent fertility of the experimental soil.

In comparing the fruits length of Yolo Wonder variety at harvest, it revealed that although, the SB medium recorded the second highest number of fruits per plant, it had the longest fruits length $(6.4 \mathrm{~cm})$ table 5 . The $\mathrm{RH}, \mathrm{CH}, \mathrm{SD}$ and $\mathrm{GH}$ had fruits lengths of $6.3,6.1$, 6.0 and $5.9 \mathrm{~cm}$ respectively, with the TS recording the shortest fruit length of $5.0 \mathrm{~cm}$ (table 5). The $\mathrm{RH}$ had the longest fruit length of $6.6 \mathrm{~cm}$ which was the longest fruit length among the California Wonder variety, followed by SD with fruit length of $6.5 \mathrm{~cm}$ (table 5). The $\mathrm{GH}$ and $\mathrm{CH}$ had fruits length of $6.1 \mathrm{~cm}$ which was third longest fruit length, whilst the TS had the shortest fruit length of 5.1 $\mathrm{cm}$ (table 5).

The $\mathrm{RH}$ and TS media recorded the shortest fruits diameter $(1.9 \mathrm{~cm})$ among the Yolo Wonder variety. The $\mathrm{SB}$ and SD had the longest fruit diameter $(2.3 \mathrm{~cm})$ followed by $\mathrm{CH}(2.1 \mathrm{~cm})$ and $\mathrm{GH}(2.0 \mathrm{~cm})$ in that order table 5. The $\mathrm{RH}$ and SD had the longest fruit diameter $(2.3 \mathrm{~cm})$ among the California Wonder variety, followed by $\mathrm{CH}$ and $\mathrm{SB}(2.2 \mathrm{~cm})$. The $\mathrm{GH}$ had the third longest fruit diameter $(2.1 \mathrm{~cm})$ with the TS recording the shortest fruit diameter (table 5).

Table 5: Effects of different media on number of fruit, fruit length and diameter of sweet pepper

\begin{tabular}{|lllllll|}
\hline & \multicolumn{2}{c}{ fruit /plant } & \multicolumn{3}{c|}{ fruit length (cm) } & \multicolumn{2}{c|}{ fruit diameter (cm) } \\
Medium & YW & CW & YW & CW & YW & CW \\
\hline RH & 10 & 11 & 6.3 & 6.6 & 1.9 & 2.3 \\
CH & 9 & 11 & 6.1 & 6.1 & 2.1 & 2.2 \\
SD & 8 & 9 & 6.0 & 6.5 & 2.3 & 2.3 \\
GH & 10 & 11 & 5.9 & 6.1 & 2.0 & 2.1 \\
SB & 9 & 11 & 6.4 & 5.8 & 2.3 & 2.2 \\
TS & 6 & 7 & 5.0 & 5.1 & 1.9 & 1.7 \\
\hline LSD & $\mathbf{2 . 3 5}$ & \multicolumn{2}{c}{$\mathbf{0 . 9 2}$} & \multicolumn{2}{c}{$\mathbf{0 . 4 4}$} \\
\hline
\end{tabular}

Incidence of diseases in the various media

None of the varieties recorded any incidence of root rot disease but there were two incidence of wilt disease in the TS within the California Wonder variety (table 6). This might probably be that the TS was already harbouring the pathogen for the disease (wilt). 
Table 6. Incidence of diseases in the various media

\begin{tabular}{|lllll|}
\hline & \multicolumn{2}{c}{ Root rot } & \multicolumn{2}{c|}{ Wilt } \\
medium & YW & CW & YW & CW \\
\hline RH & NA & NA & NA & NA \\
CH & NA & NA & NA & NA \\
SD & NA & NA & NA & NA \\
GH & NA & NA & NA & NA \\
SB & NA & NA & NA & NA \\
TS & NA & NA & NA & 2 \\
\hline
\end{tabular}

\section{CONCLUSION}

The results from the experiment showed that, soilless medium can promote growth and yield in sweet pepper than top soil. The results also indicated that, soilless medium has no or lower incidence of soil borne diseases as compared to top soil. Therefore it can be concluded that, soilless medium is a better alternative for sweet pepper cultivation.

\section{AUTHOR'S CONTRIBUTION}

The project was executed with the financial contribution from both authors. The preparation of the soilless media, potting, nursing of seeds and transplanting of seedlings were done by both authors (Michael Egyir and Bernard Awuku). Data collection, introduction and review of relevant literature was done by Bernard Awuku whilst Michael Egyir analysed and discussed the results based on the data collected and writing of other aspects of the manuscript. At the end both authors put the entire work together and read through it before submission for publication.

\section{ACKNOWLEDGEMENT}

We thank the all-knowing God for given us the strength to complete the project, despite the numerous challenges encountered.

Our profound gratitude goes to Dr. Nkrumah for his useful contribution which helped in fine tuning the final manuscript.

We also acknowledge the benevolence of the entire staff of College of Agriculture Education, University of Education Winneba, Ashanti-Manpong campus for giving us access to the greenhouse despite the heavy traffic of student users at the facility.

\section{REFERENCE}

Abdel-Monaim M. F., Abdel-Gaid M. A. \& Zayan S. A. (2014). International Journal of Agricultural Sciences ISSN: 21670447 Volume 4 (4), pp. 143-150.

Anonymous, 2000. Production guidelines for sweet pepper. http://www.hygrotech.com

(Accessed 21/10/2004).

Anonymous, (1989). Tomato and Pepper Production in the Tropics. Asian Vegetable Research and Development Center, Taiwan 1989.

Bosland P. W. and Votava E. J. (1999). Peppers: vegetable and spice capsicums. Crop Production Science in Horticulture 12. Wallingford, Oxon: CABI Publishing. Pp. 116.

Campbell A. (2006). Compost use for pest and disease suppression in NSW. $1^{\text {st }}$ edition edn, (Recycled Organics Unit, The University of New South Wales, 2006).

Díaz-Pérez, J.C., Muy-Rangel, M.D. \& Mascorro, A.G., 2007. Fruit size and Stage of Ripeness Affect Postharvest Water Loss in Bell Pepper Fruit. J. Sci. Food Agric. 87(1), 68-73.

Hadfield, J., 1993. The A-Z of Vegetable Gardening in South Africa. Struikhof Publishers, Cape Town.

Hatutale G. (2010). The effect of Plant Population and Mulching on Green pepper (Capsicum annuum L.) production under irrigation. A dissertation submitted in fulfilment of the requirements for the degree of Master of Science in Agriculture, In the Faculty of Natural and Agricultural Sciences Department of Soil, Crop and Climate Sciences University of the Free State Bloemfontein, South Africa.

Howard L. R., Smith R.T., Wagner A. B and Villalon, B, Burns E. E. (1994). Provitamin A and ascorbic acid content of fresh pepper cultivars (Capsicum annum) and processed jalapenos. Journal of Food Science, 59: 362-365.

Katan J., Waisel Y., Eshel A. \& Kafkafi U. (2002). In Plant Roots: the hidden half. 949-959 (2002).

Kelley W. T. \& Boyhan G. (2009). Commercial Pepper Production Handbook. The University of Georgia, Cooperative Extension Available at:http://pubs.caes.uga.edu/caespubs/pubs/PDF/B1309.pdf

Manrique, L. M. 1993. Greenhouse crops: A review. Journal of Plant Nutrition, 16, 2411-2477.

Mateljan G. The World's Healthiest foods. The George Mateljan foundation. USA; 2018.

Mercy E. R., David U. (2018). Potential Health Benefits of Conventional Nutrients and Phytochemicals of Capsicum peppers. Pharm Pharmacol Int J. 2018; 6(1): 62 - 69. DOI: 10.15406/ppij.2018.06.00157. Pharmacy \& Pharmacology International Journal.

Olivier, O. J., Boelema, B. H., Daiber, C. C. \& Ginsberg, L., (1981). The Cultivation of Green Peppers. No. A2, Farming in South Africa, Horticultural Research Institute, Roodeplaat, Pretoria. 